\title{
The Bonding of Additive Manufactured Ti-6Al-4V via the Powder Interlayer Bonding (PIB) Process
}

\author{
P. Davies ${ }^{1}$, H. Davies ${ }^{1}$, S. Marchisio ${ }^{2}$ \\ ${ }^{1}$ Institute of Structural Materials, College of Engineering, Bay Campus, Swansea University, Swansea, SA1 8EN, United \\ Kingdom. \\ 2 Rolls-Royce Plc, PO Box 31, Derby, DE24 8BJ, United Kingdom.
}

\begin{abstract}
$\underline{\text { Abstract }}$
Powder interlayer bonding (PIB) is a novel joining technique. The technique has been developed to facilitate high integrity repairs of aerospace components, manufactured from titanium alloys commonly employed in the aerospace industry. The PIB technique utilises an interlayer between the two faying surfaces. In this study heating was supplied via induction, enabling a bond to be created in an inert atmosphere, shielding the fusion zone from oxidation during bonding. The PIB technique proved capable of producing high integrity bonds in additive manufactured Ti-6Al-4V, where approximately $85 \%$ of the strength of the alloy is retained after bonding. Advantages of this technique over more established joining methods such as tungsten inert gas (TIG) welding and plasma arc (PA) welding include a narrow fusion zone and localised heating. It is believed that PIB can compete against these more mature techniques, providing a technique suitable for joining a range of alloys found in the aerospace industry.
\end{abstract}

Keywords: Powder Interlayer Bonding (PIB), Ti-6-4, titanium powder

Author: Dr Peter Davies, e-mail: p.d.davies@.swansea.ac.uk, Tel: 01792606144

\section{Introduction}

The drive for increased performance from gas turbines often requires more complex geometrical components to be incorporated in their design, which can result in challenging repair conditions. It is believed that the powder interlayer bonding (PIB) method will provide opportunities to salvage otherwise redundant components, potentially providing a reduction in running costs for engine suppliers where replacement components can account for approximately $70 \%$ of their maintenance costs[1]. The PIB process uses a powder interlayer between the surfaces being joined, which removes the requirement for very smooth surfaces. The bond region is heated via a Joule heating processes such as induction, which results in narrow fusion zones. Titanium's affinity for oxygen, hydrogen, nitrogen and carbon at joining temperatures requires the PIB process to be performed in an inert atmosphere which shields the weld region from oxidation.

PIB has previously demonstrated the potential[2] to be considered as a process for the repair of aerospace components. Through further development it is anticipated that the process will complement the more mature joining techniques that are commonly used to join titanium alloys such as plasma arc (PA) welding, tungsten inert gas (TIG) welding, laser beam (LB) welding[3]. Although

(C) The Authors, published by EDP Sciences. This is an open access article distributed under the terms of the Creative Commons Attribution License 4.0 (http://creativecommons.org/licenses/by/4.0/). 
these mature techniques are widely used there are some drawbacks associated with employing them. Both TIG[4] and PA[5] welding techniques produce large heat affected zones (HAZ), with distortion often affecting TIG welds[4]. Although LB welding produces small HAZ's it comes at far higher costs and can be more difficult to accurately control[6]. These processes necessitate very high temperatures at the weld region, resulting in HAZ's of varying sizes. These high temperatures produce transformed microstructures[7] when the beta transus $\left(\beta_{\mathrm{T}}\right)$ of the alloy is exceeded, and these structures have larger grains than the base alloy[8] which can negatively affect mechanical properties when compared to the original material[9].

Titanium alloys are widely utilised in the gas turbine, often contributing more than $25 \%$ of an engines total weight $[10]$. The $\alpha+\beta$ Ti-6Al-4V (Ti-6-4) alloy is extensively used in the gas turbine, often being found in the cooler regions where it is used for both structural and rotating components[11], such as casings, fan blades and discs[12]. The alloy is weldable and can be formed into complex shapes. Ti-6-4 has excellent mechanical properties with a reported $\mathrm{B}_{\mathrm{T}}$ of $996^{\circ} \mathrm{C} \pm 14^{\circ} \mathrm{C}$, fatigue strength of $500 \mathrm{MPa}$ at $10^{7}$ cycles at room temperature[13] and has been reported to have a UTS of $\sim 1050 \mathrm{MPa}$ as a rolled product[14].

More recently additive manufacturing (AM) has been used to produce net shaped complex geometrical titanium components[15]. The process is a layer on layer manufacturing technique, where a layer of the alloy is deposited upon a previous layer[16]. The process has numerous potential applications such as prototypes and component repair[17]. It is seen as an attractive process for titanium alloys offering the potential to reduce manufacturing costs through reduced machining and shorter component lead times.

\section{Experimental}

The AM Ti-6-4 material used in this study was manufactured and supplied by 3TRP. Cylinders were built in an EOS direct metal laser sintering (DMLS) machine. The flat geometry specimens were initially built into $10 \mathrm{~mm}$ diameter cylinders. Cylinders then had a thread added as shown in Figure 1a, to aid gripping before bonding. In order to assess the suitability of PIB as a manufacturing technique, more complex geometries were also produced. Curved geometries were built into $10 \mathrm{~mm}$ diameter cylinders with either a concave or convex radius at the bonding surface before also having threads added as shown in Figure $1 \mathrm{~b}+\mathrm{c}$.

Figure 1 Illustration of bonding specimens, a) flat geometry, b) concave geometry, c) convex geometry

Gas atomised Ti-6-4 powder $15-45 \mu \mathrm{m}$ in diameter, utilised for the interlayers was supplied by LPW Technology Ltd is shown in Figure 2.

Figure 2 Ti-6Al-4V powder particles used to create powder interlayers

Powder interlayers were created by combining Ti-6-4 powder with cellulose powder, glycerol and deionised water to create a paste. Powder used to create interlayers for the curved geometry bonds was sieved through a $32 \mu \mathrm{m}$ mesh before mixing into a paste. Both parts to be bonded were ultrasonically cleaned in industrial acetone for 30 minutes before the powder paste was applied. The paste was applied to one of the flat surfaces or in the case of curved geometries to the surface of the concave specimen, so that the paste protruded above the specimen edge by less than $400 \mu \mathrm{m}$, Two $\mathrm{N}$ type thermocouples were then attached to the other specimen within $1 \mathrm{~mm}$ of the faying surface and connected to a calibrated Fluke 54 II thermometer.

Both specimens being bonded were attached via collets to the rods of a servo-hydraulic rig. Faying surfaces were then brought in to contact and held at a small compressive stress of $2.5 \mathrm{MPa}$. Bonding was performed in an argon environment, shielding the fusion zone of both parts. An induction coil was used to supply a heating rate of approximately $6^{\circ} \mathrm{C}$ sec to bring the bond region temperature up to $900^{\circ} \mathrm{C}$, before a secondary heating rate of $0.5^{\circ} \mathrm{C} \mathrm{sec}$ was employed to achieve the final temperature in the $\alpha+\beta$ region. The bonding temperature was held $\left(+/-5^{\circ} \mathrm{C}\right)$ for 60 minutes. On completion of the bonding cycle the joined specimens were air cooled to room temperature. 
Completed bonds were sectioned and mounted in conductive Bakelite, then prepared via a standard grinding and polishing procedure, before being etched with Krolls Reagent to allow for metallographic analysis.

The microstructural characterisation was performed using an Hitachi SU3500 scanning electron microscope (SEM). The mean linear intercept (M.L.I.) method was used to calculate the average grain size.

Tensile specimens illustrated in Figure 3a, were machined from the bonded test pieces for subsequent mechanical testing. Room temperature tensile tests were performed in accordance with BS EN 2002-1:2005. This standard, common in the engineering industry allows the use of dual strain rates; where a relatively low strain rate is utilised during the elastic regime and through yield, followed by a higher rate to encourage failure. The changeover between strain rates prompts a step increase in the induced stress response. Nominal values of the strain reported were measured via actuator displacement. Low cycle fatigue (LCF) test specimens illustrated in Figure $3 b$ were also machined from bonded test pieces. LCF tests were performed at room temperature, with a trapezoidal waveform at $0.25 \mathrm{~Hz}$ and at an R-Ratio of 0.01 .

Figure 3 Illustration of test specimens, a) tensile, b) fatigue

\section{Results}

The microstructure of the AM material in the as received (AR) condition is illustrated in Figure 4a, displaying a columnar grain structure, with a $\beta$ grain size of approximately $150 \mu \mathrm{m}$ in width along the height of the cylinders. This structure is characteristic of the DMLS manufacturing process where partial remelting of the previous layers occurs [18]. The structure contains both aligned $\alpha$ and Widmanstatten $\alpha$ type colonies, with grains typically containing a few $\alpha$ colonies.

The PIB process had a significant effect on the microstructure through the bond region of the flat geometry specimens as illustrated in Figure 4b, producing a duplex microstructure consisting of equiaxed $\alpha_{\mathrm{p}}$ grains contained in a transformed $\beta$ matrix. The bond line was found to be $\sim 100 \mu \mathrm{m}$ thick through the centre region of the bond, containing $\sim 35 \% \alpha_{\mathrm{p}}$ volume fraction with an average $\alpha_{p}$ grain size of $\sim 8 \mu \mathrm{m}$. A limited amount of non-fusion porosity is witnessed throughout the bond line, with maximum pore size found to be below $5 \mu \mathrm{m}$ in diameter. The PIB process had a similar effect on the microstructure of both the curved

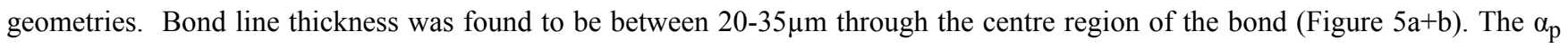
volume fraction and average $\alpha_{\mathrm{p}}$ grain size stayed consistent at $\sim 35 \%$ and $\sim 8 \mu \mathrm{m}$ respectively. Again, some non-fusion porosity was seen through the bond region, with maximum pore sizes found to be below $15 \mu \mathrm{m}$ in diameter.

Figure 4 Microstructures of a) as received additive manufactured Ti-6-4, b) bond line of PIB flat geometry

Figure 5 Microstructures of a) bond line of PIB $0.1 \mathrm{~mm}$ curved geometry b) bond line of PIB $0.5 \mathrm{~mm}$ curved geometry

The room temperature tensile results for the AR AM material and PIB bonds are shown in Figure 6. A very strong response is seen for the AR AM material with comparable strength values and higher ductility than previously reported results[18] for Ti-6-4 material built via the selective laser melting process. A reduction in UTS and ductility of $\sim 14 \%$ and $\sim 1.5 \%$ respectively is seen for the flat geometry PIB specimens (15-45 $\mu \mathrm{m}$ powder) when compared to the AR material. The curved geometry specimens provide almost the same level of strength as the flat geometry with a reduction of $\sim 15 \%$ compared to the AR material, ductility remained consistent with the flat geometry with $\sim 1.5 \%$ reduction compared to AR material. 
Figure 7 illustrates the low cycle fatigue (LCF) results for the AR AM and curved geometry materials. From the data displayed it is clear that the PIB curved geometry specimens provide an increase in LCF performance over the AR AM material. Although no run out data was recorded, both curved geometries outperform the AR material throughout the fatigue curve. At $750 \mathrm{MPa}$ the $0.1 \mathrm{~mm}$ and $0.5 \mathrm{~mm}$ curved geometries provide $\sim$ double and treble the fatigue lives recorded for the AR material.

Figure 7 LCF results for as received additive manufactured Ti-6-4 and PIB specimens

\section{Discussion}

The change in microstructure seen in the PIB specimens occurred due to the combination of temperature and force applied during the bonding cycle. The bond region was heated well into the $\alpha+\beta$ phase field during the process, combined with the applied force, enough energy is retained to enable recrystallisation to proceed during the latter stages of the bonding cycle. Previous work[2] has shown that the PIB process is akin to the sintering process; where it can be thought of as three distinct phases. Initially a small amount of deformation occurs as bonding takes place between powder particles, forming necks at the contact points. The necks grow as diffusion progresses and pores between the powders start to shrink[19]. The bulk of the deformation happens as the process continues through the intermediate phase where pores become isolated. This period is followed by the final phase where densification, and pore elimination occurs alongside the recrystallisation.

The PIB process altered the microstructure over a distance of a few millimetres from the bond line as illustrated in Figure 8 . The images show that traces of a duplex structure extend $\sim 5 \mathrm{~mm}$ away from the bond region. Beyond this distance the structure can be said to be fully lamellar, however as Figure 9 illustrates, even at $10 \mathrm{~mm}$ from the bond there is coarsening of the $\alpha$ laths compared to the AR material.

Figure 8 Illustration of the effect of the PIB process on the microstructure $\sim 5 \mathrm{~mm}$ away from the bond region

Figure 9 Illustration of the effect of the PIB process on the microstructure $\sim 10 \mathrm{~mm}$ away from the bond region

The scale of the decrease in strength seen for the PIB specimens when compared to the AR AM material is somewhat surprising. Earlier work[2] has shown that the PIB process retains over $90 \%$ of the strength of forged Ti-6-4 material. In fact, the results illustrate that both strength and ductility are almost identical to those recorded for the PIB forged material. The larger reduction in strength seen in the PIB AM specimens appears to be a consequence of the very high strength levels attained by the AR material, where both the UTS and proof strength seem exceptionally high. It is also possible that an increase in the effective slip length resulting from the coarsening of the lamellar structure contributed to a larger than expected reduction in strength.

The superior LCF performance of the PIB curved geometry specimens compared to the AR material can largely be attributed to the duplex structure through the bond region and HAZ caused by the PIB process. It is recognised that duplex structures have superior LCF performance compared to lamellar structures due to their improved resistance to crack nucleation and microcrack propagation[19].

\section{Conclusions}

- The PIB process demonstrated it is capable of producing high integrity bonds in additive manufacturing Ti-6-4 material

- High levels of strength and ductility are retained in the material post bonding 
- The LCF performance of PIB material exceeds that of the base additive manufacturing Ti-6-4 material

\section{6. $\underline{\text { References }}$}

[1] S. Ackert, "Engine Maintenance Concepts for Financiers,” Aircr. Monit., no. 2, p. 30, 2011.

[2] P. Davies, A. Johal, H. Davies, and S. Marchisio, "Powder Interlayer Bonding of Titanium alloys: Ti-6Al-2Sn-4Zr-6Mo and Ti-6Al-4V," J. Adv. Manuf. Technol., 2019.

[3] J. Forsdike, "Novel Joining and Repair of Aerospace Materials,” 2009.

[4] S. Lathabai, B. L. Jarvis, and K. J. Barton, "Comparison of keyhole and conventional gas tungsten arc welds in commercially pure titanium," Mater. Sci. Eng. A, vol. 299, no. 1-2, pp. 81-93, 2001.

[5] K. Weman, Welding processes handbook, 2nd ed. Woodhead Publishing, 2012.

[6] E. Akman, A. Demir, T. Canel, and T. Sinmazçelik, "Laser welding of Ti6Al4V titanium alloys," J. Mater. Process. Technol., vol. 209, no. 8, pp. 3705-3713, 2009.

[7] G. Lütjering and J. C. Williams, Titanium, 2nd ed. Springer, 2007.

[8] S. Sundaresan, G. D. Janaki Ram, and G. Madhusudhan Reddy, "Microstructural refinement of weld fusion zones in $\alpha-\beta$ titanium alloys using pulsed current welding," Mater. Sci. Eng. A, vol. 262, no. 1-2, pp. 88-100, 1999.

[9] W. B. L. and R. F. K.C. Winco Yung, Ralph, “An investigation into welding parameters affecting the tensile properties oftitanium welds,” J. ofMaterials Process. Technol., vol. 63, no. 96, pp. 759-764, 1997.

[10] M. Peters, J. Kumpfert, C. H. Ward, and C. Leyens, "Titanium alloys for aerospace applications," Adv. Eng. Mater., vol. 5, no. 6, pp. 419-427, 2003.

[11] I. Inagaki, T. Tsutomu, S. Yoshihisa, and A. Nozomu, "Application and Features of Titanium for the Aerospace Industry," 2014.

[12] J. S. Hewitt, P. D. Davies, M. J. Thomas, P. Garratt, and M. R. Bache, "Titanium alloy developments for aeroengine fan systems,” Mater. Sci. Technol., vol. 30, no. 15, pp. 1919-1924, 2014.

[13] "Properties and processing of TIMETAL 6-4, TIMET Brochure."

[14] M. Davies, P., Whittaker, M., \& Thomas, "Development of a new alpha/beta titanium alloy for gas turbine aerofoils," in In Materials Science and Technology Conference and Exhibition, 2013, pp. 2975-2982.

[15] B. Baufeld, O. Van der Biest, and R. Gault, "Additive manufacturing of Ti-6Al-4V components by shaped metal deposition: Microstructure and mechanical properties,” Mater. Des., vol. 31, no. SUPPL. 1, pp. S106-S111, 2010.

[16] W. E. Frazier, “Metal additive manufacturing: A review,” J. Mater. Eng. Perform., vol. 23, no. 6, pp. 1917-1928, 2014.

[17] P. A. Kobryn and S. L. Semiatin, "Mechanical Properties of Laser-Deposited Ti-6Al-4V P.A. Kobryn and S.L. Semiatin Air Force Research Laboratory, AFRL/MLLMP, Wright-Patterson Air Force Base, OH 45433-7817,” pp. 179-186, 2013.

[18] T. Vilaro, C. Colin, and J. D. Bartout, “As-fabricated and heat-treated microstructures of the Ti-6Al-4V alloy processed by selective laser melting,” Metall. Mater. Trans. A Phys. Metall. Mater. Sci., vol. 42, no. 10, pp. 3190-3199, 2011.

[19] H. Djohari, J. I. Martínez-Herrera, and J. J. Derby, "Transport mechanisms and densification during sintering: I. Viscous flow versus vacancy diffusion,” Chem. Eng. Sci., vol. 64, no. 17, pp. 3799-3809, 2009. 

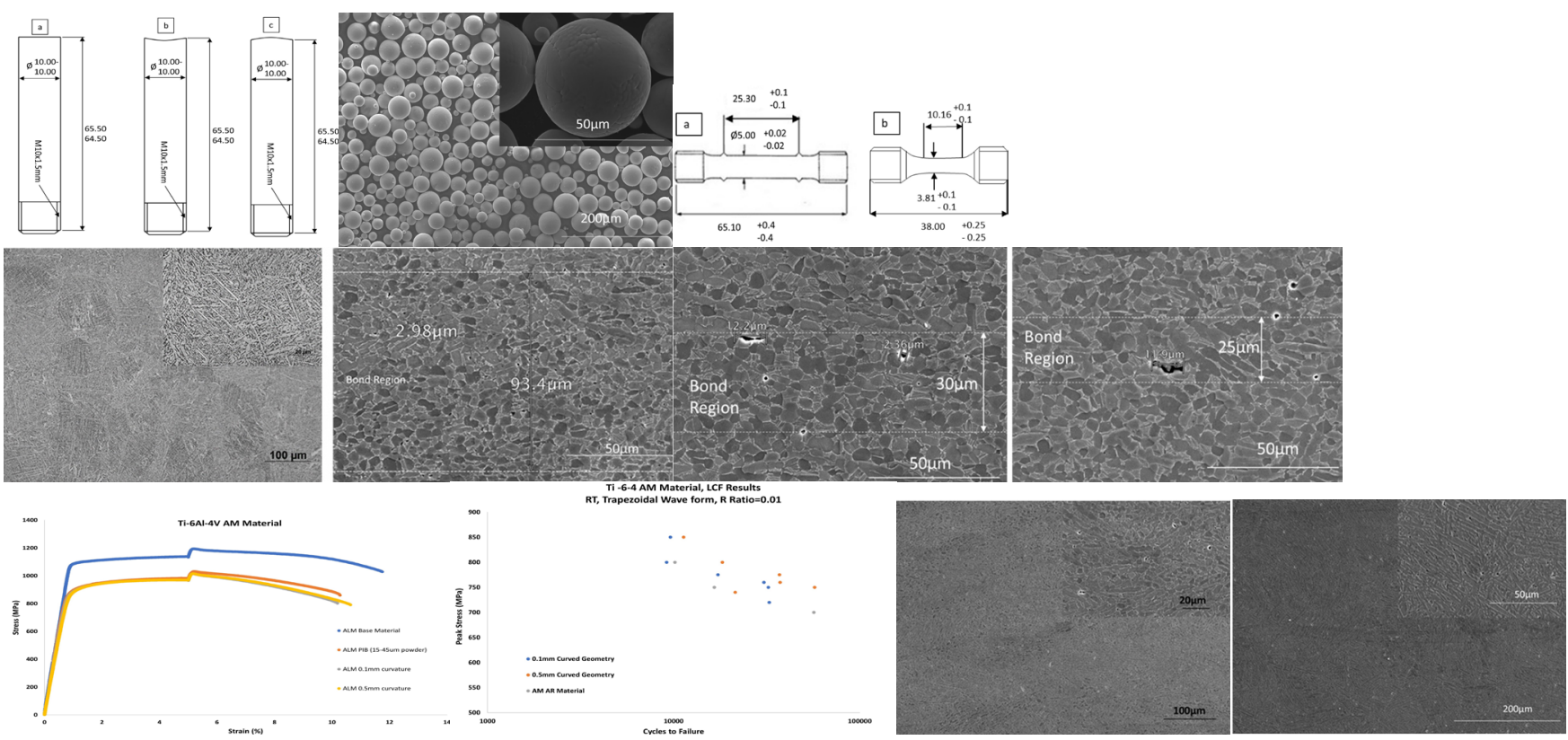